\title{
Antibody Screening of Healthy Blood Donors: It's Time to Make it Mandatory
}

\section{Gopal Kumar Patidar}

Blood Bank, Adlakha Medical Centre, Amritsar, Punjab-143001, India

*Corresponding author: Gopal Kumar Patidar, Blood Bank, Adlakha Medical Centre, Amritsar, Punjab-143001, India, Tel: 919781089405; E-mail:

drgpatidar@gmail.com

Received date: Nov 18, 2014, Accepted date: Jan 16, 2015, Publication date: Jan 19, 2015

Copyright: ( 2015 Patidar GK. This is an open-access article distributed under the terms of the Creative Commons Attribution License, which permits unrestricted use, distribution, and reproduction in any medium, provided the original author and source are credited.

Red cell unexpected alloantibodies can be present in healthy donors who were either transfused previously or pregnant previously. Presence of irregular erythrocyte alloantibodies can occasionally cause severe transfusion reaction if a large amount of plasma or whole blood is transfused as in massive transfusions and in pediatric patients. Here we are presenting a case report of a donor who had red cell alloantibody. The purpose of highlighting this case report is to know the significance of detecting irregular erythrocyte antibodies in healthy donors.

\section{Abstract \\ Keywords: Blood Donor; Antibody Screening \\ Antibody Screening of Healthy Blood Donors: It's Time to Make it Mandatory}

There are two types of antibodies that are of concern in blood banking: one is naturally occurring and the other is immune. Both are produced in reaction to encountered antigens. $\mathrm{RBC}$ antibodies are considered naturally occurring when they are found in the serum of individuals who have never been previously exposed to RBC antigens by transfusion, injection, or pregnancy.

Naturally occurring anti-A and anti-B antibodies are routinely detected in human serum and are easily detected by use of A and B reagent $\mathrm{RBCs}$ with a direct agglutination technique. In normal healthy individuals anti-A and anti-B are generally the only RBC antibodies expected to be found in a serum sample [1].

All other antibodies directed against RBC antigens are considered unexpected and must be detected and identified before blood can be safely transfused. The reactivity of unexpected antibodies is highly varied and unpredictable. These antibodies may be able to hemolyze the red cell of the patient's, the in-vitro analysis of unexpected antibodies involves the use of antibody screening procedures to optimize antigen-antibody reactions [1]. The majority of these procedures include reacting unknown serum from a donor or patient sample with known reagent. All routine blood bank testing requires the use of samples for both expected and unexpected antibodies.

These unexpected alloantibodies can be present in healthy donors who were either transfused previously or pregnant previously. Occurrence of alloantibodies is higher in females due to childbearing and transfusions. There is a paucity of literature on the prevalence of irregular erythrocyte antibodies in the general population. Alloantibodies have been detected in up to $0.8 \%$ of blood donors, $2 \%-$ $9 \%$ of patients with a history of blood transfusion and $9 \%-30 \%$ in patients who receive chronic transfusion therapy like sickle cell anaemia, beta-Thalassemia or hematologic malignancies [2]. Screening of donated blood for the presence of irregular erythrocyte antibodies has been laid down in the guidelines of the National Blood Policy, India, 2007 (National Aids Control Organization, Ministry of Health
\& Family Welfare) [3]. The incidence of transfusion or haemolytic reactions due to irregular erythrocyte alloantibodies in donor blood is a relatively rare [4]. Presence of irregular erythrocyte alloantibodies can occasionally cause severe transfusion reaction if a large amount of plasma or whole blood is transfused as in massive transfusions and in pediatric patients. Only packed red blood cells should be preferably transfused when irregular erythrocyte antibodies are found, as these antibodies present in plasma can cause immune haemolysis in recipients. Here we are presenting a case report of a donor who had red cell alloantibodies.

\section{Case Report}

A 37 years old male donor came to us for donating blood at our blood bank. On testing his blood group it was found "A Rh D negative". On putting indirect antiglobulin test (IAT) of donor serum with pooled $\mathrm{O}$ cell it was found positive. On antibody screen and with commercial 3 cell panel on glass bead technology (Orthodiagnostic Pvt. Ltd.) it showed positive reaction and on antibody identification with 11 cell panel (Orthodiagnostic Pvt. Ltd.) it showed anti-D and anti-C alloantibody. Select cell panel test also confirmed the above findings. These antibodies had IgG specificity. When the donor was asked for a detail history of transfusion it was found that he was transfused 12 years back for fracture femur surgery. Donor informed us that at that time A Rh D negative blood was not available in the inventory of the hospital so that they transfused with $\mathrm{A} \mathrm{Rh} \mathrm{D}$ positive to him. No Anti-D immunoglobulin was given to him.

\section{Discussion}

Although screening of donated blood for the presence of irregular erythrocyte antibodies has been laid down in the guidelines of the National Blood Policy, India, 2007 (National Aids Control Organization, Ministry of Health \& Family Welfare) [3] but still it is not a mandatory procedure in India. Some blood banks are still not performing the IAT test with Rh Negative donor samples. This came to our knowledge when the donor informed us that he donated 5 times in between the first transfusion and the current donation at our blood bank. It was for the first time he was detected and informed regarding irregular red cell alloantibodies in his blood. 
There are only a few studies for incidence of irregular red cell alloantibody in healthy donors in India. A study by Pahuja et al. [5] shows incidence of $0.05 \%$ in their donor population. In another study Garg et al. [6] found $0.09 \%$ prevalence of red cell alloantibody. Although there is a low prevalence in normal healthy donor population, but the significance of irregular erythrocyte antibodies can be that large amount of plasma or whole blood is transfused as in massive transfusions and in paediatric patients.

It is recommended that only packed red blood cells should be issued when irregular antibodies are found in the blood unit as the plasma component has the potential to cause immune hemolysis in recipients [7]. But for paediatric patients the use of such packed red blood cells should be avoided [2].

Screening of the donors plasma is a relatively simple test and capable of detecting potent antibodies to the clinically significant antigens. There have been many advances in automation on screening for irregular erythrocyte alloantibodies.

\section{Conclusion}

IAT of donated blood is not being done in many centers across India because of decentralized and fragmented blood transfusion services. Screening donor sera for antibodies serves to simplify the work of cross-matching by eliminating the need for the minor cross match. The purpose of highlighting this case report is to know the significance of detecting irregular erythrocyte antibodies in healthy donors. Large-scale studies are required to assess the magnitude of IAT in donors and to assess the clinical significance of the same.

\section{References}

1. Harmening DM (2005) Modern blood banking and transfusion practices. United States of America: 60.

2. Hamilton JR (2009) Common and frequently encountered antibodies. Transfus Apher Sci 40: 189-194.

3. http://www.naco.gov.in/upload/2014\%20mslns/BTS/National\%20Blood \%20Policy.pdf

4. Mohn JF, Lambert RM, Bowman HS, et al. (1961) Experimental transfusion of donor plasma containing blood group antibodies into incompatible normal human recipients. I. Absence of destruction of red cell mass with anti-Rh, anti-Kell and anti-M. Brit J Haemat 7: 112.

5. Pahuja S, Kushwaha S, Sethi N, Pujani M, Jain M (2012) Screening of blood donors for erythrocyte alloantibodies. Hematology 17: 302-305.

6. Garg N, Sharma T, Singh B (2014) Prevalence of irregular red blood cell antibodies among healthy blood donors in Delhi population. Transfus Apher Sci 50: 415-417.

7. Myhre Ba, Greenwalt Tj, Gajewski M (1965) Incidence of Irregular Antibodies Occurring in Healthy Donor Sera. Transfusion 5: 350-354. 